\title{
MICROPHYSICAL PROPERTIES OF WARM CLOUDS DURING THE AIRCRAFT TAKE-OFF AND LANDING OVER BUCHAREST, ROMANIA
}

\author{
${ }^{1 *}$ Sabina Stefan, ${ }^{1,2}$ Sorin Nicolae Vajaiac, ${ }^{1,2}$ Andreea Boscornea \\ ${ }^{1}$ University of Bucharest, Faculty of Physics, P.O.BOX, MG-11, Magurele, Bucharest, Romania, \\ *Email: sabina_stefan@yahoo.com \\ ${ }^{2}$ National Institute for Aerospace Research "Elie Carafoli" (INCAS), Bucharest, Romania
}

\begin{abstract}
This paper is focused on airborne measurements of microphysical parameters into warm clouds when the aircraft penetrates the cloud, both during take-off and landing. The experiment was conducted during the aircraft flight between Bucharest and Craiova, in the southern part of Romania. The duration of the experimental flight was 2 hours and 35 minutes in October 7th, 2014, but the present study is dealing solely with the analysis of cloud microphysical properties at the beginning of the experiment (during the aircraft take-off) and at the end, when it got finalized by the aircraft landing procedure. The processing and interpretation of the measurements showed the differences between microphysical parameters, emphasizing that the type of cloud over Bucharest changed, as it was expected. In addition, the results showed that it is important to take into account both the synoptic context and the cloud perturbation due to the velocity of the aircraft, in such cases.
\end{abstract}

\section{INTRODUCTION}

Cloud systems are the most important components of the atmosphere. The microphysical properties of clouds play an important role in weather forecasting, in the radiative and energetic budget of the earth, and, as such, in climatological studies [1]. The parameterization of cloud radiative properties, which is important for climatic models, depends on the parameterization of microphysical parameters like effective radius, drop size distributions and liquid water content (LWC) [2].

The drop/droplets concentrations and their size distributions are influenced by environment conditions, especially by temperature, pressure and atmospheric aerosol particles concentrations [3].
This study was designed to analyze the microphysical parameters during a take-off and landing procedures over the Bucharest airport, in time of an experimental flight between Bucharest and Craiova, which are two cities in southern part of Romania.

The details about the flight, the instruments of the Airborne Laboratory and the methods used for measurement processing are included in Section 2, namely "Methodology". Section 3 of the study discusses the results and their interpretation, which confirms the importance of microphysical proprieties knowledge. The paper ends with some conclusions.

\section{METHODOLOGY}

The flight started with the profiling of a cloud layer above Bucharest. Following this, the flight was in line toward Craiova, and close to Craiova, the aircraft made a vertical sounding. After one hour, the aircraft flew back toward Bucharest, and it finished with the landing procedure, which occurred into a thick cloud over Bucharest. In our study, we found it necessary to examine the properties of the clouds during the procedures of take-off and landing. The measurements were carried out with CAPS system mounted on the left wing of aircraft Beechcraft C90 GTx, which is part of the Airborne Laboratory for Environmental Atmospheric Research in the National Institute for Aerospace Research "Elie Carafoli" (INCAS), in Bucharest, Romania.

The CAPS (Cloud Aerosol Spectrometer Precipitation) was used for measurements. The CAPS system has two components: CAS (Cloud and Aerosol Spectrometer) for small particles/droplets ( 0.51 to $50 \mu \mathrm{m})$ and CIP (Cloud Imagine Particles) for big droplets (15 to $930 \mathrm{um}$ with optional 15 -micron resolution). This system provides information about the effective diameter of cloud/aerosol particles, their concentrations, LWC (liquid water content), the atmospheric 
temperature and pressure. The CAS is based on light-scattering by smaller particles [4]. CAS records just droplets which are suspended in the air indefinitely, and, in addition to this, CIP recorded the falling precipitation drops. The number of particles of different sizes is stored in Bin channels and the effective diameters are differently defined.

\section{RESULTS}

The first part of the flight, from Bucharest, is a standard take-off procedure and is then continued with a horizontal line. The lowest altitude of the first part of the flight was observed at the beginning, namely at $672 \mathrm{~m}$, and the highest occurred when the aircraft moved to horizontal position, at $3300 \mathrm{~m}$. During this first part of our analysis, the temperature started from $9^{\circ} \mathrm{C}$ and did not go beyond the negative temperature of $-3^{\circ} \mathrm{C}$, at the highest altitude. However, the cloud layer got up to $1{ }^{\circ} \mathrm{C}$ and its thickness had a value of $1732 \mathrm{~m}$. These macroscopic characteristics indicate a warm/water cloud with cloud top at $2360 \mathrm{~m}$. During the slow cloud penetration by the aircraft (which lasted for 4 minutes), the variations of the microphysical parameters were determined using CAS and CIP measurements (Fig. 1 upper panel).

In the case of aircraft landing, the temperatures have positive values that increased from $3^{\circ} \mathrm{C}$ to $10^{\circ} \mathrm{C}$. It is known [5] that the radii values of the particles/cloud droplets are the result of a few important processes in warm clouds, as follows: a) the heterogeneous nucleation of cloud droplets on $\mathrm{CCN}$ (cloud condensation nuclei), $\mathrm{r} \sim 1 \mu \mathrm{m}$; b) the growth by diffusion of water vapor up to $\mathrm{r} \sim 20$ $\mu \mathrm{m}$; c) growth by collision and coalescence up to $\mathrm{r} \sim 100 \mu \mathrm{m}$; and, d) precipitation $\mathrm{r} \geq 100 \mu \mathrm{m}$. In Fig. 1 upper panel one can note the variation with the height of the microphysical parameter values inside of the warm cloud. Thus, the variation with the height of effective diameters show that there are aerosol particles at cloud base, small cloud droplets due to $\mathrm{CCN}$ presence and large cloud droplets (cloud drops radius between 30 and 100 $\mu \mathrm{m})$ due to collision-coalescence or accretion processes. Toward the cloud top, the radius of the droplets increases and the radius of the cloud drops decreases.
The high droplets' concentration in the cloud is associated with small size particles (Fig.1 upper panel).

The measurements with CIP show low drop concentrations: $\max 20 \mathrm{~cm}^{-3}$ at cloud base to 140 $\mathrm{cm}^{-3}$ close to the cloud top. These results are similar to Pruppacher and Klett (1997) observations for continental water clouds.

The microphysical parameters in the time of aircraft landing are displayed in Fig.1 lower panel. The microphysical parameters are very different from those observed at the time of aircraft take-off (Fig.1 lower panel). This means that the meteorological conditions changed over Bucharest, as well as the cloudy system. The increasing of the cloud drops radii determined the decreasing of their number concentrations, which is explained by the enhancement of collision coalescence processes (Fig.1 lower panel).

In the last part of the flight, during the landing procedure, the dynamics of processes inside the cloud were accelerated due to the aircraft velocity and the temperature and pressure variations.
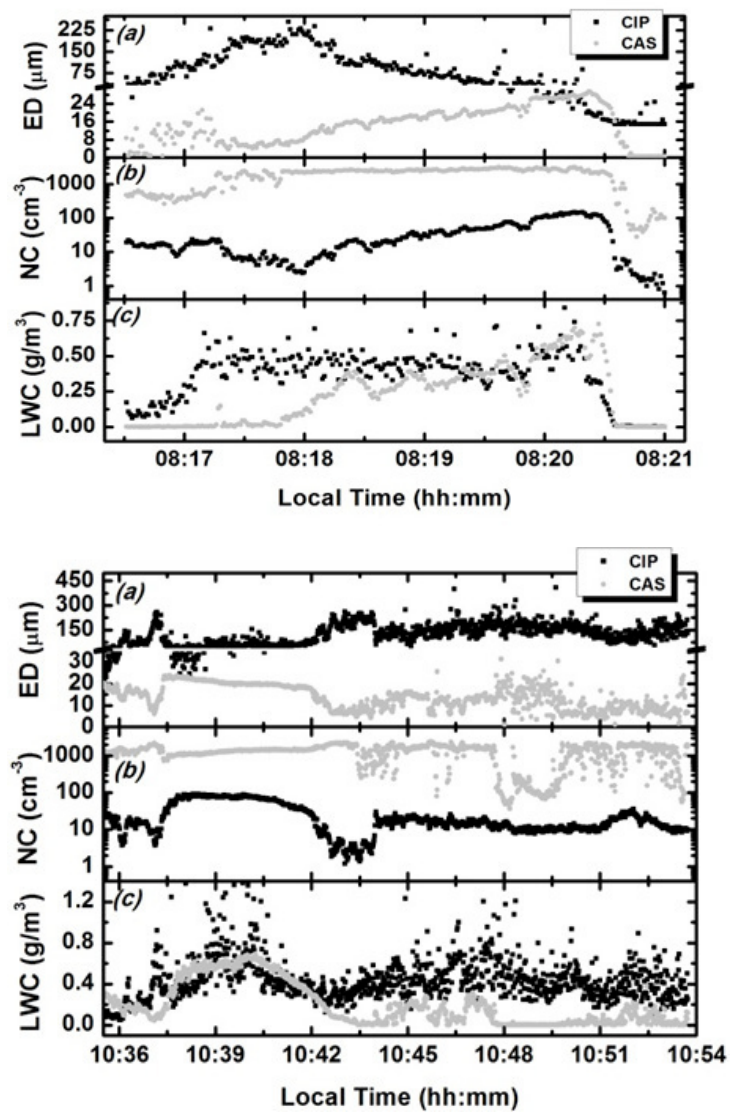

Fig.1 Effective diameter, number concentration and LWC measured by CAS and CIP in clouds 
over Bucharest during take-off (upper panel) and during landing (lower panel)

The microphysical parameters are very different than those from the time of aircraft take-off.

The liquid water content (LWC) (Figs.1 and 2) varies as per the number concentrations of drops.

It is noteworthy that in the first meters, the values of LWC are small $\left(0.05 \mathrm{~g} \mathrm{~m}^{-3}\right)$, as was expected due to the aerosol dominance. LWC increases with height above the cloud base (at $628 \mathrm{~m}$ ), up to $0.7 \mathrm{~g} \mathrm{~m}^{-3}$.

The variation of LWC with height into cloud during aircraft ascension, and the variation during the landing procedure are different, which emphasizes the difference between the cloud types. At the beginning of the flight, it was stratus and, after two hours, the nimbostratus cloud covered the sky airport area over Bucharest.

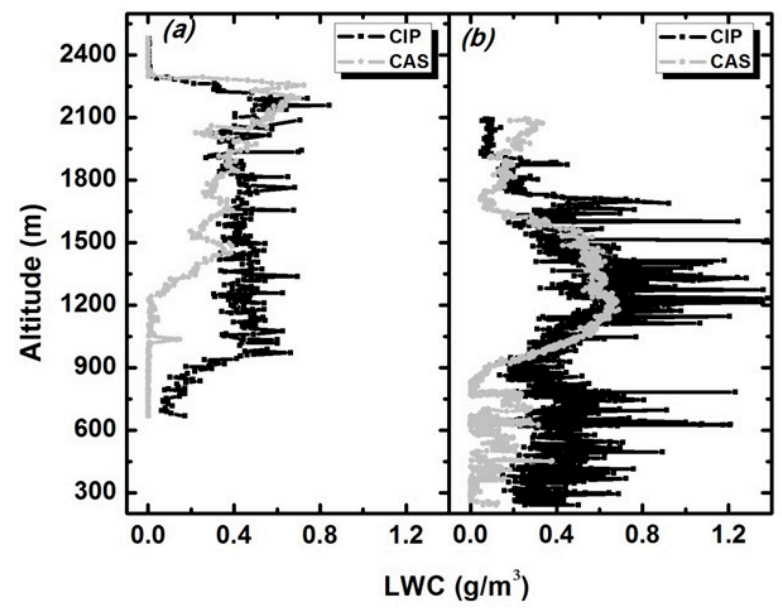

Fig.2 Variation of LWC with height during aircraft take-off (a) and during landing (b)

\section{CONCLUSIONS}

The aircraft measurements during the flight on October 072014 were used to investigate the properties of the clouds.

The discrepancy or the similarity of effective diameters for cases with significantly different number concentrations, and in consequence, with different LWC, can be attributed to both meteorological (temperature, dynamics) and microphysical factors, associated to differences in the cloud types.

The cases presented here highlight the microphysical parameters values (according to
Pruppacher and Klett (1997) data) presence of warm clouds as follows: the aircraft take-off was into stratus cloud, and, lastly, the cloud system over Bucharest was a precipitating nimbostratus. Combined analyses of the CAS and CIP microphysical measurements lead to better insights into the key processes within clouds.

We have shown that the remote sensing measurements provide an important context for the interpretation of the microphysics measurements, and extend them along trajectories for interpreting the evolution of hydrometeors within clouds.

\section{ACKNOWLEDGEMENT}

This work is supported by the project Clouds and Aerosols Profiling in support of ESA's sentinel 4 and 5 missions (CAPESA), which take place under program Technology Space and Advanced Research (STAR), Romanian Space Agency (ROSA).The work of the first author, Sabina Stefan, was supported by the national project PNII-PT-PCCA-2013-4-2074.

\section{REFERENCES}

[1] Intergovernmental Panel on Climate Change (IPCC), Climate Change 2007: The Physical Science Basis. UK: Cambridge University Press, 2007.

[2] Pawlowska, Hanna, J. L. Brenguier, and Frederic Burnet, (2000): Microphysical properties of stratocumulus clouds, Atmospheric research 55.1, 15-33.

[3] Sharon, T. M., B. A. Albrecht, H. H. Jonsson, P. Minnis, M. M. Khaiyer, T. M. van Reken, J. Seinfeld, and R. Flagan, 2006: Aerosol and cloud microphysical characteristics of rifts and gradients in maritime stratocumulus clouds. Journal of the atmospheric sciences, 63, 983-997.

[4] D. Baumgardner, H. Jonsson, W. Dawson, D. O'Connor, and R. Newton, 2001, The cloud, aerosol and precipitation spectrometer: A new instrument for cloud investigations, Atmospheric research, 59, 251-264.

[5] Pruppacher, H. R., and J. D. Klett, 1997: Microphysics of Clouds and Precipitation. Published by Kluwer Academic Publisher, 714 pp. 